\title{
Wound-Healing Properties of Green (Using Lawsonia Inermis Leaf Extract) and Chemically Synthesized Zno Nanoparticles in Albino Rats
}

Asmaa A. Metwally

Aswan University

Abdel-Nasser A.A. Abdel-Hady

South Valley University Faculty of Veterinary Medicine

Mohie A.M. Haridy

South Valley University Faculty of Veterinary Medicine

Khaled Ebnalwaled

South Valley University Faculty of Science

AbdulRahman A Saied ( $\nabla$ saied_abdelrahman@yahoo.com )

National Food Safety Authority https://orcid.org/0000-0001-8616-5874

Ahmed S. Soliman

Cairo University Faculty of Veterinary Medicine

\section{Research Article}

Keywords: ZnO Nanoparticle, Characterization, Green synthesis, Lawsonia inermis, Gel, Wound healing

Posted Date: July 6th, 2021

DOl: https://doi.org/10.21203/rs.3.rs-639379/v1

License: (9) (i) This work is licensed under a Creative Commons Attribution 4.0 International License.

Read Full License

Version of Record: A version of this preprint was published at Environmental Science and Pollution Research on November 24th, 2021. See the published version at https://doi.org/10.1007/s11356-02117670-5. 


\section{Abstract}

Wound healing is one of the utmost medical issues in human and veterinary medicine, which explains the urgent need for developing new agents that possess wound-healing activities. The present study aimed to assess the effectiveness of green and chemical ZnO-NPs for wound healing. ZnO-NPs (chemical and green using Lawsonia inermis leaf extract) were synthesized and characterized by XRD; FTIR, and HRTEM. The gels containing the nanomaterials were prepared and inspected. Forty-five albino rats were divided into three groups, the control group was treated with normal saline $0.9 \%$ and the other two groups were treated with gels containing green and chemical ZnO-NPs, respectively. On the 3rd, 7th, 14th, and $21 \mathrm{st} \mathrm{dpt}$, the wounds were clinical and histologically examined. Both nanomaterials have good crystallinity and high purity, but green ZnO-NPs have a longer nanowire length and diameter than chemical ZnO-NPs. The formed gels were highly viscous with a pH of 6.5 to 7. Both prepared gels showed clinical improvements, such as a decrease in WSA and WSA\%, increase in WC\%, and reduced healing time $(P<0.05)$ in both treated groups when compared with control group. The histological scoring of this study showed that the epithelization score was significantly higher at $21 \mathrm{st} \mathrm{dpt}$ in treated groups than in the control group $(P<0.05)$, but the vasculature, necrosis, connective tissue formation, and collagen synthesis scores were mostly similar. The green and chemical ZnO-NPs gels showed promising wound healing properties however, the $L /$ mediated-ZnO-NPs were more effective.

\section{Introduction}

The skin is a vital multifunctional organ, and to restore the normal skin anatomy and functions, the wound healing must be rapid and free of complications (Karodi et al. 2009). The ability of the skin to heal wounds quickly and effectively is critical for maintaining natural healthy skin (Christian et al. 2006). Nanotechnology, a rapidly growing and challenging research area, has piqued scientists' interest in a variety of biomedical applications, (Akbar et al. 2020). Nanoparticles have been introduced into various life aspects such as industry, health, food, biomedical and cosmetics industry. ZnO-NPs are the most interesting of the inorganic metal oxides due to they are inexpensive to manufacture, clean, and simple to prepare (Jayaseelan et al. 2012). Zinc oxide nanoparticles (ZnO-NPs) are one of the most commonly used metal oxide nanoparticles for biomedical purposes such as wound healing, antimicrobial, and antiinflammatory properties (Gunalan et al. 2012; Varghese and George 2015).

Green nanoparticle synthesis is appealing as a potential alternative to chemical and physical methods. Plant-mediated nanoparticle synthesis is an environmentally friendly, cost-effective, and safe method (Gan and Li 2012; Kouvaris et al. 2012; Akbar et al. 2020). Lawsonia inermis (Henna) is a well-known plant that has been studied in herbal medicine. Leaves extracts have shown various biological activities and are used as a wound dressing as it accelerated wound healing and also or its antimicrobial properties (Nayak et al. 2007; I Towfik et al. 2014; Rekik et al. 2019).

This study aimed to investigate the wound healing properties of chemically and green (using methanolic extract of Lawsonia Inermis leaves) synthesized ZnO-NPs in cutaneous wounds of albino rats. Both 
nanomaterials were physicochemically characterized. Clinical and histological evaluations were used to assess their effectiveness in wound healing.

\section{Materials And Methods \\ Chemicals and Reagents}

Methanol was purchased from Lab Scan Analytical Sciences, Poland. Activated charcoal powder was purchased from ADWIA Company, Egypt. Potassium dichromate of Analytical Reagent (AR) grade was used without any further purification. Zinc nitrate hexahydrate (Zn (NO3)2・6H20) 99\% was obtained from (Oxford, USA). Diethyl ether and Carbopol $940 \AA$ were purchased from Loba Chemie Company, India. All other chemicals and solvents were of analytical grade.

\section{Plant Material}

Commercial dried leaves of Lawsonia inermis (Henna) were purchased from a local market at Aswan city (latitude $24^{\circ} 5^{\prime} 15^{\prime \prime} \mathrm{N}$; longitude $32^{\circ} 53^{\prime} 56^{\prime \prime} \mathrm{E}$ ), the southern part of Egypt, and identified by the Department of Botany, Faculty of Science, South Valley University. Leaves were screened and the good ones were selected to be ground into a fine powder using an electric blender.

\section{Extract preparation}

Dried leaves of Lawsonia inermis were soaked in $80 \%$ methanol at a 1:10 ratio in an Erlenmeyer flask covered with aluminum foil for 24 hours, with periodic agitation. Activated charcoal was added to the extract and left for $15 \mathrm{~min}$ for chemical depigmentation. Then, the extract was filtrated by Whatman filter paper No. 1 and the filtrate was vacuum dried in a rotary evaporator (Heidolph, Germany) at $45^{\circ} \mathrm{C}$. The extract was stored at $4^{\circ} \mathrm{C}$ till the preparation of green ZnO-NPs.

\section{Synthesis of nanoparticles}

Zinc oxide nanoparticles were chemically prepared by placing zinc nitrate hexahydrate $[0.1 \mathrm{M}, \mathrm{Zn}$ (NO3)2.6 $\mathrm{H} 2 \mathrm{O}$ ] in a water bath at $60^{\circ} \mathrm{C}$, then $0.4 \mathrm{M}$ of sodium hydroxide was dropped under gentle stirring. The mixture was sealed under heating and stirring for 2 hours. Then the precipitation was separated and washed several times. Finally, the products were dried using a hot air oven at $60^{\circ} \mathrm{C}$ for about 8 hours. Zinc oxide nanoparticles were prepared via henna extract by dissolving zinc nitrate hexahydrate $(0.1 \mathrm{M})$ in 40 $\mathrm{mL}$ of distilled water. Then $20 \mathrm{~mL}$ of henna extract solution was added with continuous stirring at $150^{\circ} \mathrm{C}$ for 2-3 hrs until completely dissolved. The resultant mixture was cooled at room temperature, and the supernatant was discarded. The resultant solid product (pale white in color) was centrifuged twice at $6000 \mathrm{rpm}$ for $10 \mathrm{~min}$. Finally, the solid precipitate was dried at $60^{\circ} \mathrm{C}$ for about 8 hours and used for further studies.

\section{Characterization of nanoparticles}


To investigate the physicochemical properties of the prepared green and chemically synthesized samples, one gram from each sample was sent to the Egyptian Petroleum Research Institute (EPRI) for characterization. The X-ray powder diffraction (XRD) pattern was used to investigate nanostructural properties and purity of the prepared $\mathrm{ZnO}$ nanoparticles using PANalytical X'Pert PRO diffractometer operated with Cuka radiation $(\mathrm{k}=1.54060 \mathrm{~nm})$ and $\mathrm{X}$-ray radiation (X-ray generator current and voltage set at $40 \mathrm{~mA}$ and $40 \mathrm{Kv}$ ). The diffractograms were recorded in the $2 \theta$ range of 4-90 with a $2 \theta$ step size of 0.02 and a step time of $0.7 \mathrm{~s}$. Fourier-transform infrared spectra (FTIR) analysis was used to investigate the chemical composition of the prepared nanoparticles. It was performed by Nicolet IS-10 model (USA) infrared spectrophotometer in the range of wavenumber of $4000-400 \mathrm{~cm}-1$. The structural morphology of prepared nanoparticles was observed by transmission electron microscope (TEM) using highresolution JEOL - 2100FTEM (Japan) at $200 \mathrm{kV}$.

\section{Preparation of gels}

Gels were prepared according to Zaid et al., (Zaid et al. 2017) Green or chemical ZnO-NPs (200mg) were dissolved in $20 \mathrm{ml} 1 \%$ acetic acid and placed on a hot plate magnetic stirrer then cooled. Distilled water $(100 \mathrm{ml})$ was poured into the mixer, and then $1 \mathrm{~g}$ Carbopol $940 \AA$ was slowly added, followed by the addition of the studied nanomaterials solutions until the formation of the gel with a concentration of $0.2 \%$, which was then stored at $-20^{\circ} \mathrm{C}$ for further use.

\section{Characters of gels}

The gels were visually inspected for their physical properties, such as color, transparency, homogeneity, and $\mathrm{pH}$. Skin irritation was evaluated by topical application of $2 \mathrm{~g}$ of the gel on the back of the hand and observing for any lesions, irritation, or redness according to Kumar et al., (Kumar 2017). It's important to measure the gel capacity to absorb wound exudates before using it for biological applications or wound healing. Each nanoparticle's gel $(10 \mathrm{~g})$ was weighed and placed in $10 \mathrm{ml}$ of distilled water and the weight of gel was measured after the $1 \mathrm{st}, 2 \mathrm{nd}, 3 \mathrm{rd}$ hours. The water absorption capacity of the gel was determined in triplicate and calculated according to Tvl et al., (Tvl et al. 2010) using a formula:

$\%$ Water absorption capacity $=\frac{\text { Final weight-Initial weight }}{\text { Initial weight }} \times 100$

\section{Animals and experimental design}

Forty-five adult female albino rats (weighted $180 \pm 200 \mathrm{gm}, 8-12$ weeks old) were purchased from Abou Rewash Farm, Giza, Egypt, and housed for one week with standard environmental conditions, constant temperature, and humidity with natural light/dark cycle before carrying out the experiment. They were kept in plastic cages with wire mesh covers, received a standard pellet diet and water ad libitum throughout the experimental period. Animals were divided into three groups (15 rats each); Group 1 was used as a control group and their cutaneous wounds were treated with $0.9 \%$ saline solution. Groups 2 and 3 were treated topically with gels containing green and chemically synthesized ZnO-NPs, respectively. All treatments were applied every other day for 21 days. The animals were maintained and used in 
accordance with the guidelines of the Animal Ethics Committee in the Faculty of Veterinary Medicine at South Valley University, Qena, Egypt (approval no. VM-2019-0017).

\section{Wound healing studies \\ Clinical evaluations}

The wounds were clinically and histologically examined and photographed at the 3rd, 7th, 14th, $21 \mathrm{st}$ dpt. The diameter of the wounds was measured by using a digital caliper. The healing time, wound surface area, wound surface area percent, and wound contraction percent were evaluated using the following equations:

Healing time $=($ date of healing (DH) - date of wounding (DW)) (Ramos and Miranda 2007).

Wound surface area (WSA) $=\pi r^{2}\left(\mathrm{~cm}^{2}\right)$ (Zaid et al. 2017)

Where $\pi(\mathrm{Pi})$ is a mathematical constant $(22 / 7)$ and $\mathrm{r}^{2}$ is the radius squared.

Wound surface area percent (WSAP \%) $=\frac{\text { Wound surface area } \times 100}{0.50} \%$.

Wound contraction percent (WCP $\%)=100 \%$ - WSAP $\%$.

\section{Histopathological studies}

After euthanasia of rats by a high dose of diethyl ether, specimens from skin wounds with surrounding normal skin (about $1.5 \mathrm{~cm}$ ) on the 3rd, 7th, 14th, and $21 \mathrm{st}$ dpt were harvested and fixed in $10 \%$ buffered formalin and dehydrated using upgraded concentrations of ethyl alcohol. The tissue specimens were embedded in paraffin wax melting point at $58-60^{\circ} \mathrm{C}$. Sections about $5 \mu \mathrm{m}$ thickness were prepared and stained with hematoxylin and eosin according to Bancroft and Gamble (Bancroft and Gamble 2008) and stained with Morrison Crossman stain to detect collagen fibers (Kim et al. 2013). Also, neovascularization, epithelialization, collagen production, and necrosis were evaluated qualitatively (Zayed et al.; Abbaszadeh et al. 2019).

\section{Statistical Analysis}

The study results were presented as mean values \pm standard deviations (SD). One-way analysis of variance (ANOVA) was used to statistically analyze the obtained data using computerized SPSS (SPSS statistics Ver. 16) software. A value of $p \leq 0.05$ is considered statistically significant.

\section{Results And Discussion}

\section{Characterization of nanoparticles}


Characterization of nanoparticles provides essential information about their size, shape, surface charge, surface area and, dispersity (Jayaseelan et al. 2012). The XRD of the prepared ZnO-NPs samples is shown in Fig. 1. All detectable peaks can be indexed as the ZnO-NPs hexagonal wurtzite-type structure in the standard data (JCPDS, 36-1451) (Ghamsari et al. 2019). The synthesized ZnO-NPs have good crystallinity and are of high purity. The FTIR revealed the asymmetric molecular stretching, vibration, and rotation of chemical bonds when exposed to the designated wavelengths of light. As shown in Fig. 2, the FTIR spectra of the prepared Green / Chemical ZnO nanoparticles showed that the main absorption bands at $3500,2354,1720,1514$, and $1220 \mathrm{~cm}^{-1}$, which correspond to $\mathrm{O}-\mathrm{H}$ mode, CO2 mode, O-H mode, and asymmetric and symmetric $\mathrm{C}=\mathrm{O}$ stretching modes, respectively. The intense broadband in the vicinity of $418 \mathrm{~cm}^{-1}$ is the characteristic absorption peak of $\mathrm{Zn}-\mathrm{O}$ bond and also authenticates the presence of $\mathrm{ZnO}$ the same results were obtained by Kwon et al. (Kwon et al. 2002) Silva and Zainiquelli (Silva and Zaniquelli 2002); Li et al. (Li et al. 2004); Kim et al. (Kim et al. 2005); Liufu et al. (Liufu et al. 2005) and Labuayai et al. (Labuayai et al. 2009). The TEM as shown in Fig. 3, revealed that ZnO-NPs consist of nanowires as the prepared ZnO-NPs and TEM images confirmed the hexagonal structure of the synthesized ZnO-NPs. Green ZnO-NPs have wires length and wires diameter more than the obtained ZnO nanoparticles by chemical method. It is well documented that decreasing particle size increases their functionality as antimicrobial and anticancer agents due to the larger surface-to-volume ratio (Selim et al. 2020). The phase and purity of the prepared samples is unaffected by the preparation methods, indicating that the green method using Lawsonia inermis leaves is an effective method for the preparation of $\mathrm{ZnO}$ nanoparticles, which in turn confirms that green technology is superior to physical and chemical methods for producing nanoparticles (Rosi and Mirkin 2005; Gnanajobitha et al. 2013; Vidya et al. 2013; Parveen et al. 2016). Our study has confirmed that the synthesized green ZnO-NPs, possess a smaller particle size, enhanced the wound healing activity due to the large surface area to volume ratio and surface reactivity when compared to the synthesized chemical ZnO-NPs (Gunalan et al. 2012).

\section{Characters of gels}

Green and chemically synthesized ZnO-NPs gels are translucent in color as shown in Fig. 4. The gels were highly viscous and homogenous, stable, and spread out easily on the skin surface. The gels $\mathrm{pH}$ was 6.5 to 7 , so there is no detectable itching or hypersensitivity reaction. The level of water absorption capacity $\%$ of gels containing nanoparticles at the $1 \mathrm{st}, 2 \mathrm{nd}$ and $3 \mathrm{rd}$ hours are shown in Fig. 5 . The potential of green ZnO-NPs gel to absorb water is higher than that of chemically synthesized ZnO-NPs gel at the different periods of the experiment. Carbopol hydrogels loaded with a bioactive agent have been reported to accelerate the healing process, and improve the tissue quality of burn wounds (Singh et al. 2017). It maintains a moist environment within the wound site as a vehicle for topical administration. Maximum swelling of carbomer $940 \AA$ was observed in simulated wound fluid (Singh et al. 2017). Therefore, we used Carbopol $940 \AA$ as a vehicle for our studied nanomaterials. Our study results agreed with Morgado et al. (Morgado et al. 2015), who reported that the ideal wound dressing should be able to absorb exudates from the wound bed where water absorption or hydrophilicity allows the penetration of nutrients, cells, and bioactive molecules. 


\section{Clinical picture of the wounds}

Grossly as in Fig. 6, swelling and hyperemia of the wound edges were observed on the day of wounding. On the 3rd dpt, wounds of rats in green ZnO-NPs and ZnO-NPs groups were lost their rounded forms and covered with moist reddish-brown scabs, and their wound contraction was increased with less exudate formation. In contrast, the wounds of rats in the control group were covered with moist scabs, and there was clearly noticeable yellowish exudate and edema through the wound edges. On the 7th dpt, wounds of rats in green ZnO-NPs and ZnO-NPs groups were covered with thin dry scabs, and the wound size of rats in green ZnO-NPs group was non significantly narrower than those in rats of ZnO-NPs group. The wounds of the control group were covered with thick moist scab and with less contraction when significantly compared with green ZnO-NPs and ZnO-NPs groups. On the 14th dpt, the wounds were covered with small and dry scab in individual rats in green ZnO-NPs and ZnO-NPs groups. The wounds of rats of the control group were covered with a relatively thick scab. On the $21 \mathrm{st} \mathrm{dpt}$, the scab sloughed from wounds of rats in green ZnO-NPs and ZnO-NPs groups leaving scar tissue, which was relatively clearer in rats of group 3 than those of green ZnO-NPs group. Meanwhile, the control group showed a clear red scar.

Wound surface area (WSA) is shown in Fig. 7. Wound surface area percent (WSA \%) is shown in Fig. 8, and Wound contraction percent (WC \%) is shown in Fig. 9. At 7th dpt, WSA and WSA\% significantly decreased in both ZnO-NPs treated groups, compared with the control group. While at the 7th dpt, WC\% significantly increased in both ZnO-NPs treated groups (chemical and green) compared with the control group. Furthermore, at the 3rd, 14th and 21 st days PT WSA, WSA\% and WC\% showed no significance between the treated groups or the control group when $p \leq 0.05$. As shown in Fig. 10, the healing time of wounds is significantly decreased $(p \leq 0.05)$ in rats of green ZnO-NPs and ZnO-NPs groups when compared with the control group.

\section{Histopathological findings}

The wound gap of the control group showed large blood clots, necrotic tissue, the appearance of fibroblastic proliferation under the scabs, and there was edema and abundant neutrophils infiltration as well at the 3rd dpt, however at the 7th dpt they showed fibroblastic proliferation and abundant cell infiltration mainly macrophage with newly formed blood vessels perpendicular on the wound edge. At the 14th $\mathrm{dpt}$, the wound gap showed fibroblast proliferation with collagen-rich production associated with extensive inflammatory cells infiltration. At the $21 \mathrm{st} \mathrm{dpt}$, the wounds showed granulation tissue covered with epidermis with inflammatory cell infiltration beneath the granulation tissue as shown in Fig. 11. The wound gap of green ZnO-NPs group revealed necrotic tissues with a little blood clot, edema, and heavy infiltration with inflammatory cells, mainly neutrophils at the 3rd dpt. Meanwhile, they showed predominant fibroblast proliferation with collagenous fibers-rich production, high cellular macrophages, and lymphocytes infiltration with newly-formed blood vessel formation at the 7th dpt. At the 14th dpt, wounds showed a noticeable re-epithelization of the granulation tissue with less inflammatory cell infiltration and abundant collagenous fibers. At the $21 \mathrm{st} \mathrm{dpt}$, the wounds showed complete reepithelization and intact epidermis with minimal inflammatory cell infiltration, and neoformed blood 
vessel formation, and rich mature scar formation as shown in Fig. 11. At the 3rd dpt, wound gaps of ZnONPs group were filled with extravasation of RBCs, edema, and aggregation of neutrophils. At the 7th dpt, wounds showed the presence of granulation tissue in the gap with hemorrhage and aggregation of neutrophils and eosinophils. At the 14th dpt, the wound gap decreased in size with complete reepithelization and proliferation of fibroblasts and collagenous fiber production with a smaller number of inflammatory cells. At the $21 \mathrm{st} \mathrm{dpt}$, remarkable epithelization with heavily collage fibers production was observed. Also, minimal fibroblasts and infiltration with neutrophils and macrophages were noticed as shown in Fig. 11.

\section{Wound-healing histological scoring}

The score of wound healing (epithelization, vasculature, necrosis, connective tissue formation, and collagen synthesis) was qualitatively evaluated in all animals as shown in Fig. 12. The epithelization was not significantly changed at the 3rd, 7th, and 14th dpt in green ZnO-NPs and ZnO-NPs groups in comparison to those of the control group but was significantly increased $(p \leq 0.05)$ at the 21 st dpt. It was noticeable that the vasculature, necrosis, connective tissue formation, and collagen synthesis at the 3rd, 7th, 14th, and 21st dpt were not significantly changed in green ZnO-NPs and ZnO-NPs groups when compared to the control group.

Lawsonia inermis is one of the plants that accelerates the wound healing process via reducing the epithelialization period and increasing the wound contraction percent (Yassine et al. 2020). The topical application of $L$. inermis rapidly initiates the inflammatory process by enhancing higher inflammatory cell infiltration and subsequently reduce the inflammatory phase by inhibiting monocyte-to-macrophage differentiation (Daemi et al. 2019). It is reported that Lawsonia inermis leaves extract to contain flavonoids, alkaloids, and terpenoids, which accelerate the phenomena of wound healing by their astringent and antibacterial activities (James and Friday 2010; Bapat and Mhapsekar 2014), prevention of cell necrosis, improvement of angiogenesis (Fikru et al. 2012), inhibition of prostaglandin synthesis (Jain et al. 2011), and modulation of cytokines expression during the inflammation phase (AntunesRicardo et al. 2015). L. inermis methanolic extracts showed antibacterial effects against different bacteria (Elansary et al. 2020; Nigussie et al. 2021) i.e. LI inhibits the growth of gram-positive and gramnegative bacteria (Pasandi Pour and Farahbakhsh 2020). LI has strong antifungal and antioxidant activities (Elansary et al. 2020). ZnO-NPs accelerate the collagen synthesis and wound contraction with a relatively reduced scar (Saremi et al. 2016), regulate the endogenous growth factors and insulin-like growth factor-l, which may increase epithelialization (Ågren et al. 1991; Tarnow et al. 1994; Ågren 1999; Li et al. 2006; Aksoy et al. 2010; Sazegar et al. 2011; Arslan et al. 2012). Microscopically, ZnO-NPs had a beneficial impact on skin repair. ZnO-NPs enhanced angiogenesis, platelet activation re-epithelialization, and debris removal. ZnO-NPs achieve effective wound closure, aesthetic wound closure-healing power, and they can act as antimicrobial adhesives for the tissues (Batool et al. 2021). ZnO enhanced collagen deposition via the migration of a greater number of fibroblasts to the wound site (Kumar et al. 2013). It's attributed that the healing action of ZnO-NPs is due to the zinc ions, which enhance re-epithelization through keratinocyte migration to the wound site (Kumar et al. 2012). Therefore, and as a result of the 
synergistic effect, the ZnO Nanoparticles were synthesized using Lawsonia leaves methanolic extract to improve the antibiotic and wound healing activities of both. Our study revealed that the $\mathrm{ZnO}$ nanoparticles synthesized using Lawsonia inermis methanolic extract are more effective than the chemically synthesized ZnO NPs in the acceleration of wound healing, re-epithelization, fibroblasts stimulation, reducing inflammation and scar formation (Metwally et al. 2020).

\section{Conclusions}

We have concluded that the green synthesis of zinc oxide nanoparticles using the methanolic extract of Lawsonia inermis leaves produced pure, smaller nanoparticles having more effective wound healing efficacy than the chemically synthesized ZnO-NPs. Therefore, in the future, green ZnO-NPs containing formulations may be utilized as an effective wound healing agent in humans and animals.

\section{Declarations}

\section{Ethics approval and consent to participate}

The animals were maintained and used in accordance with the guidelines of the Animal Ethics Committee in the Faculty of Veterinary Medicine at South Valley University, Qena, Egypt (approval no. VM2019-0017).

\section{Declaration of competing interest}

The authors declare that they have no known competing financial interests or personal relationships that could have appeared to influence the work reported in this paper.

\section{Funding}

The study was supported financially by Aswan University, Aswan, Egypt.

\section{Authors' contributions}

ASS and AAA, put the study design, AAM, carried out the experimental procedures and statistical analysis, $\mathrm{KhE}$, prepared the nanoparticles, MAM, performed the interpretation of pathological samples, AAS, prepared the studied gels and helped in their evaluation tests, wrote and edited the manuscript. All authors have read and agreed to the published version of the manuscript.

\section{Acknowledgements}

The authors would like to thank Dr. Marwa A. Moghazy, Environmental Applications of Nanomaterials Lab., Chemistry Department, Faculty of Science, Aswan University, Aswan, Egypt for her help in analyzing the characterized nanoparticles.

\section{Data Availability}


Not applicable.

\section{Consent for publication}

Not applicable.

\section{References}

1. Abbaszadeh A, Rajabzadeh A, Zarei L (2019) Effect of Chitosan/Propolis Biodegradable Film on FullThickness Wound Healing in Rats. Iran J Vet Surg 14:9-17

2. Ågren MS (1999) Zinc in wound repair. Arch Dermatol 135:1273-a

3. Ågren MS, Chvapil M, Franzén L (1991) Enhancement of re-epithelialization with topical zinc oxide in porcine partial-thickness wounds. J Surg Res 50:101-105

4. Akbar S, Tauseef I, Subhan F, et al (2020) An overview of the plant-mediated synthesis of zinc oxide nanoparticles and their antimicrobial potential. Inorg Nano-Metal Chem 50:257-271

5. Aksoy B, Atakan N, Aksoy HM, et al (2010) Effectiveness of topical zinc oxide application on hypertrophic scar development in rabbits. Burns 36:1027-1035

6. Antunes-Ricardo M, Gutierrez-Uribe J, O Serna-Saldivar S (2015) Anti-inflammatory glycosylated flavonoids as therapeutic agents for treatment of diabetes-impaired wounds. Curr Top Med Chem 15:2456-2463

7. Arslan K, Karahan O, Okus A, et al (2012) Comparison of topical zinc oxide and silver sulfadiazine in burn wounds: an experimental study. Ulus Travma Acil Cerrahi Derg 18:376-383

8. Bancroft JD, Gamble M (2008) Theory and practice of histological techniques. Elsevier health sciences

9. Bapat UC, Mhapsekar DR (2014) Phytochemical investigations and antimicrobial and anticancer activities of Homonoia riparia Lour. Int J Pharm Pharm Sci 6:237-243

10. Batool M, Khurshid S, Qureshi Z, Daoush WM (2021) Adsorption, antimicrobial and wound healing activities of biosynthesised zinc oxide nanoparticles. Chem Pap 75:893-907

11. Christian LM, Graham JE, Padgett DA, et al (2006) Stress and wound healing. Neuroimmunomodulation 13:337-346

12. Daemi A, Farahpour MR, Oryan A, et al (2019) Topical administration of hydroethanolic extract of Lawsonia inermis (henna) accelerates excisional wound healing process by reducing tissue inflammation and amplifying glucose uptake. Kaohsiung J Med Sci 35:24-32

13. Elansary HO, Szopa A, Kubica P, et al (2020) Antioxidant and biological activities of Acacia saligna and Lawsonia inermis natural populations. Plants 9:908

14. Fikru A, Makonnen E, Eguale T, et al (2012) Evaluation of in vivo wound healing activity of methanol extract of Achyranthes aspera L. J Ethnopharmacol 143:469-474 
15. Gan PP, Li SFY (2012) Potential of plant as a biological factory to synthesize gold and silver nanoparticles and their applications. Rev Environ Sci Bio/Technology 11:169-206

16. Ghamsari MS, Alamdari S, Razzaghi D, Pirlar MA (2019) ZnO nanocrystals with narrow-band blue emission. J Lumin 205:508-518

17. Gnanajobitha G, Paulkumar K, Vanaja M, et al (2013) Fruit-mediated synthesis of silver nanoparticles using Vitis vinifera and evaluation of their antimicrobial efficacy. J Nanostructure Chem 3:1-6

18. Gunalan S, Sivaraj R, Rajendran V (2012) Green synthesized ZnO nanoparticles against bacterial and fungal pathogens. Prog Nat Sci Mater Int 22:693-700

19. I Towfik A, Hamza SS, K Munahi A (2014) The effect of Henna (Lawsonia inermis) on the wound healing of local Arabian horses. J kerbala Univ 10:78-91

20. Jain AK, Jain CP, Gaur K, et al (2011) Evaluation of antinociceptive and anti-inflammatory activity of leaves of Cassia grandis Linn. Int J Pharm Clin Res 2:106-108

21. James O, Friday ET (2010) Phytochemical composition, bioactivity and wound healing potential of Euphorbia heterophylla (Euphorbiaceae) leaf extract. Int J Pharm Biomed Res 1:54-63

22. Jayaseelan C, Rahuman AA, Kirthi AV, et al (2012) Novel microbial route to synthesize ZnO nanoparticles using Aeromonas hydrophila and their activity against pathogenic bacteria and fungi. Spectrochim Acta Part A Mol Biomol Spectrosc 90:78-84

23. Karodi R, Jadhav M, Rub R, Bafna A (2009) Evaluation of the wound healing activity of a crude extract of Rubia cordifolia L.(Indian madder) in mice. Int J Appl Res Nat Prod 2:12-18

24. Kim J, Lee J, Lyoo YS, et al (2013) The effects of topical mesenchymal stem cell transplantation in canine experimental cutaneous wounds. Vet Dermatol 24:242-e53

25. Kim Y-S, Tai W-P, Shu S-J (2005) Effect of preheating temperature on structural and optical properties of ZnO thin films by sol-gel process. Thin Solid Films 491:153-160

26. Kouvaris P, Delimitis A, Zaspalis V, et al (2012) Green synthesis and characterization of silver nanoparticles produced using Arbutus Unedo leaf extract. Mater Lett 76:18-20

27. Kumar A (2017) A Comparative Study on the Efficacy of Chitosan Gel Formulation and Conventional Silver Sulfadiazine Treatment in Healing Burn Wound Injury at Molecular Level. Asian J Pharm Free full text Artic from Asian J Pharm 11:

28. Kumar PT, Lakshmanan V-K, Biswas R, et al (2012) Synthesis and biological evaluation of chitin hydrogel/nano ZnO composite bandage as antibacterial wound dressing. J Biomed Nanotechnol 8:891-900

29. Kumar S, Lakshmanan V-K, Raj M, et al (2013) Evaluation of wound healing potential of $\beta$-chitin hydrogel/nano zinc oxide composite bandage. Pharm Res 30:523-537

30. Kwon YJ, Kim KH, Lim CS, Shim KB (2002) Characterization of ZnO nanopowders synthesized by the polymerized complex method via an organochemical route. J Ceram Process Res 3:146-149

31. Labuayai S, Promarak V, Maensiri S (2009) Synthesis and optical properties of nanocrystalline ZnO powders prepared by a direct thermal decomposition route. Appl Phys A 94:755-761 
32. Li H, Wang J, Liu H, et al (2004) Sol-gel preparation of transparent zinc oxide films with highly preferential crystal orientation. Vacuum 77:57-62

33. Li X, Yin J, Li D, et al (2006) Dietary supplementation with zinc oxide increases IGF-I and IGF-I receptor gene expression in the small intestine of weanling piglets. J Nutr 136:1786-1791

34. Liufu S-C, Xiao H-N, Li Y-P (2005) Thermal analysis and degradation mechanism of polyacrylate/ZnO nanocomposites. Polym Degrad Stab 87:103-110

35. Metwally A, Abdel-Hady A-NAA, Ebnalwaled K, et al (2020) Wound-healing activity of green and chemical zinc oxide nanoparticles (ZnO-NPs) gels in equine wounds: a clinical study. SVUInternational J Vet Sci 3:66-79

36. Morgado PI, Aguiar-Ricardo A, Correia IJ (2015) Asymmetric membranes as ideal wound dressings: An overview on production methods, structure, properties and performance relationship. J Memb Sci 490:139-151

37. Nayak BS, Isitor G, Davis EM, Pillai GK (2007) The evidence based wound healing activity of Lawsonia inermis Linn. Phyther Res An Int J Devoted to Pharmacol Toxicol Eval Nat Prod Deriv 21:827-831

38. Nigussie D, Davey G, Legesse BA, et al (2021) Antibacterial activity of methanol extracts of the leaves of three medicinal plants against selected bacteria isolated from wounds of lymphoedema patients. BMC Complement Med Ther 21:1-10

39. Parveen K, Banse V, Ledwani L (2016) Green synthesis of nanoparticles: their advantages and disadvantages. In: AIP conference proceedings. AIP Publishing LLC, p 20048

40. Pasandi Pour A, Farahbakhsh H (2020) Lawsonia inermis L. leaves aqueous extract as a natural antioxidant and antibacterial product. Nat Prod Res 34:3399-3403

41. Ramos AFN, Miranda JL de (2007) Propolis: a review of its anti-inflammatory and healing actions. J Venom Anim Toxins Incl Trop Dis 13:697-710

42. Rekik DM, Khedir S Ben, Daoud A, et al (2019) Wound Healing Effect of Lawsonia inermis. Skin Pharmacol Physiol 32:295-306

43. Rosi NL, Mirkin CA (2005) Nanostructures in biodiagnostics. Chem Rev 105:1547-1562

44. Saremi Z, Yari R, Khodadadi I, Tabatabaei SM (2016) The Combined Effects of Nano-Zinc, NanoAlbumin and Honey in Healing Wounds Caused by Third-Degree Burn in Male Mice. J Ski Stem Cell 3:

45. Sazegar G, Reza AHS, Behravan E (2011) The effects of supplemental zinc and honey on wound healing in rats. Iran J Basic Med Sci 14:391

46. Selim YA, Azb MA, Ragab I, Abd El-Azim MHM (2020) Green synthesis of zinc oxide nanoparticles using aqueous extract of Deverra tortuosa and their cytotoxic activities. Sci Rep 10:1-9

47. Silva RF, Zaniquelli MED (2002) Morphology of nanometric size particulate aluminium-doped zinc oxide films. Colloids Surfaces A Physicochem Eng Asp 198:551-558

48. Singh B, Sharma A, Sharma A, Dhiman A (2017) Design of antibiotic drug loaded carbopolcrosslinked-poly (2-hydroxyethylmethacrylate) hydrogel for wound dressing applications. 
Am J Drug Deliv Ther 4:1-9

49. Tarnow P, Ågren M, Steenfos H, Jansson J-O (1994) Topical zinc oxide treatment increases endogenous gene expression of insulin-like growth factor-1 in granulation tissue from porcine wounds. Scand J Plast Reconstr Surg hand Surg 28:255-259

50. Tvl HB, Vidyavathi M, Kavitha K, Sastry TP (2010) Preparation and evaluation of ciprofloxacin loaded chitosan-gelatin composite films for wound healing activity. Int J Drug Deliv 2:

51. Varghese E, George M (2015) Green synthesis of zinc oxide nanoparticles. Int J Adv Res Sci Eng 4:

52. Vidya C, Hiremath S, Chandraprabha MN, et al (2013) Green synthesis of ZnO nanoparticles by Calotropis gigantea. Int J Curr Eng Technol 1:118-120

53. Yassine KA, Houari H, Mokhtar B, et al (2020) A topical ointment formulation containing leaves' powder of Lawsonia inermis accelerate excision wound healing in Wistar rats. Vet World 13:1280

54. Zaid A, Sharshar A, Abd-El-Gaber M, Abdel-Rahman HA (2017) Effect of Chitosan Gel on Wound Healing: Experimental Study in Donkeys. Alexandria J Vet Sci 53:

55. Zayed M, Haridy M, Misk N, Abd-El-Hady A-N Surgical and Histopathol-ogical Evaluation of Suture Materials for Closure of Colonic Wounds after Experimental Typhlectomy in Dogs

\section{Tables}

Table 1. Botanical information and percentage yields of the leaf extract.

\begin{tabular}{|llllll|}
\hline Plant species & Family & Local name & Plant part used & Extract pH & Extract yield (\%) \\
\hline Lawsonia inermis & Lythraceae & Henna & Leaves & 5.6 & 5 \\
\hline
\end{tabular}

\section{Figures}




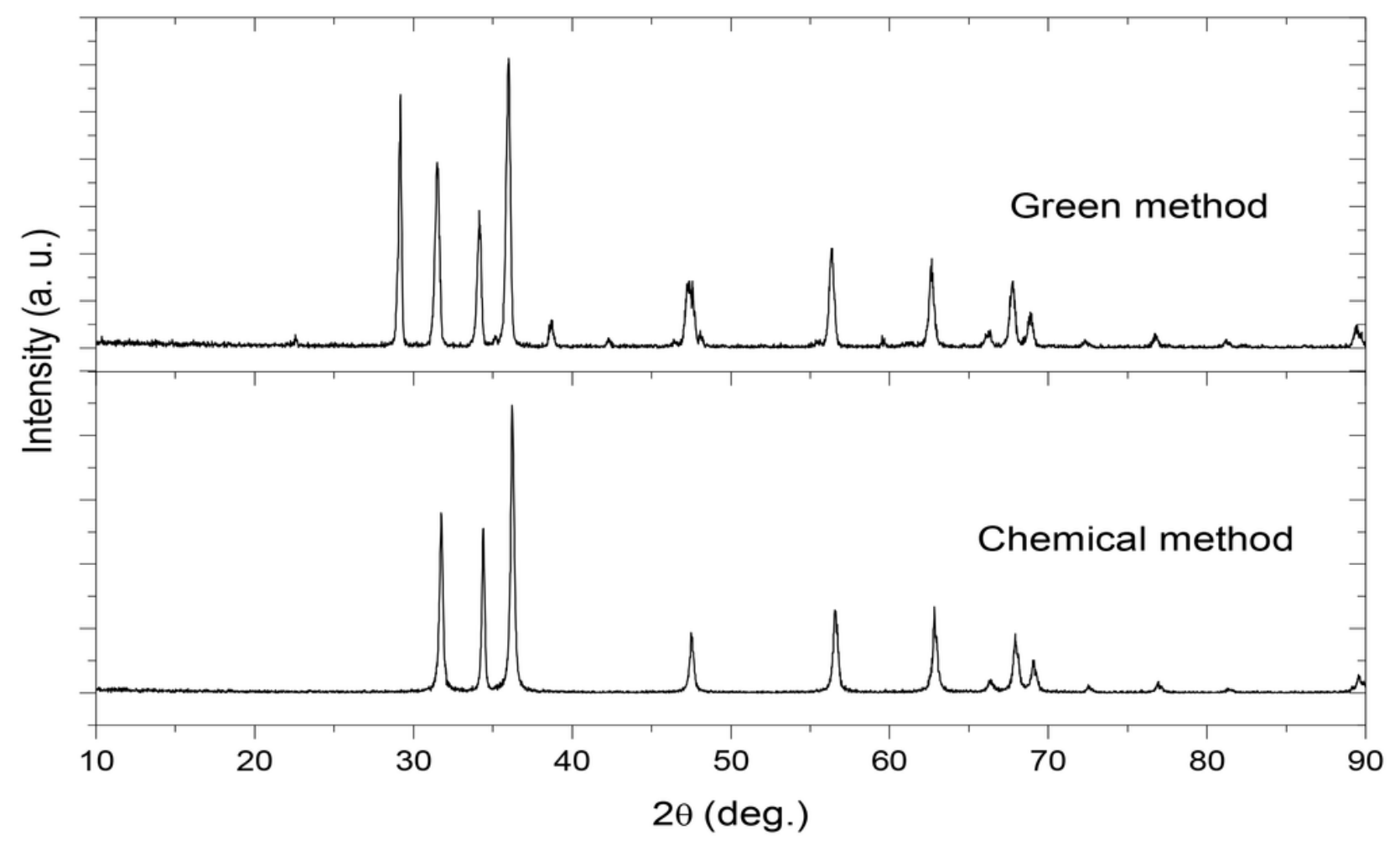

Figure 1

XRD for the prepared ZnO nanoparticles. 


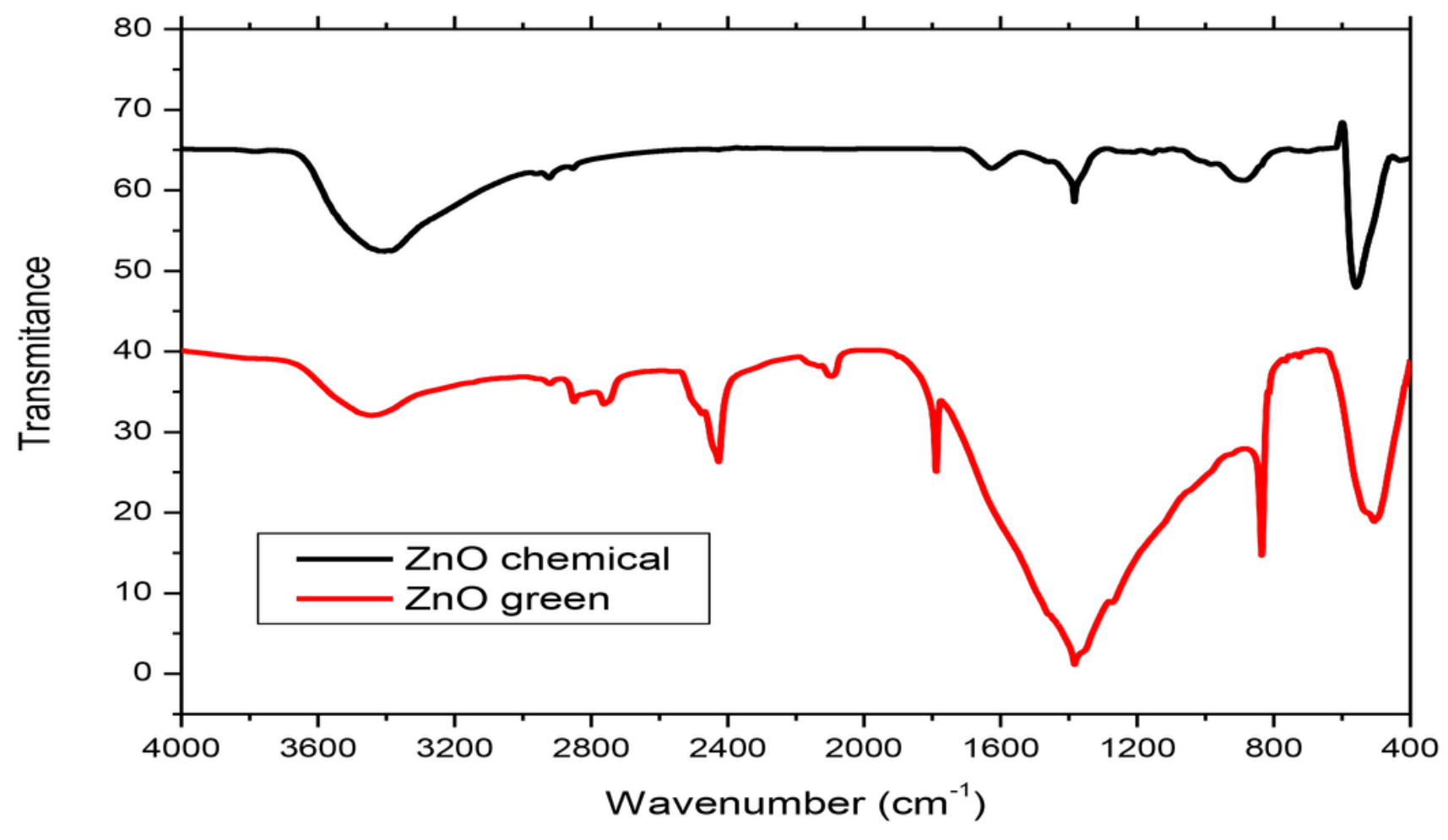

Figure 2

FTIR for the prepared $\mathrm{ZnO}$ nanoparticles. 

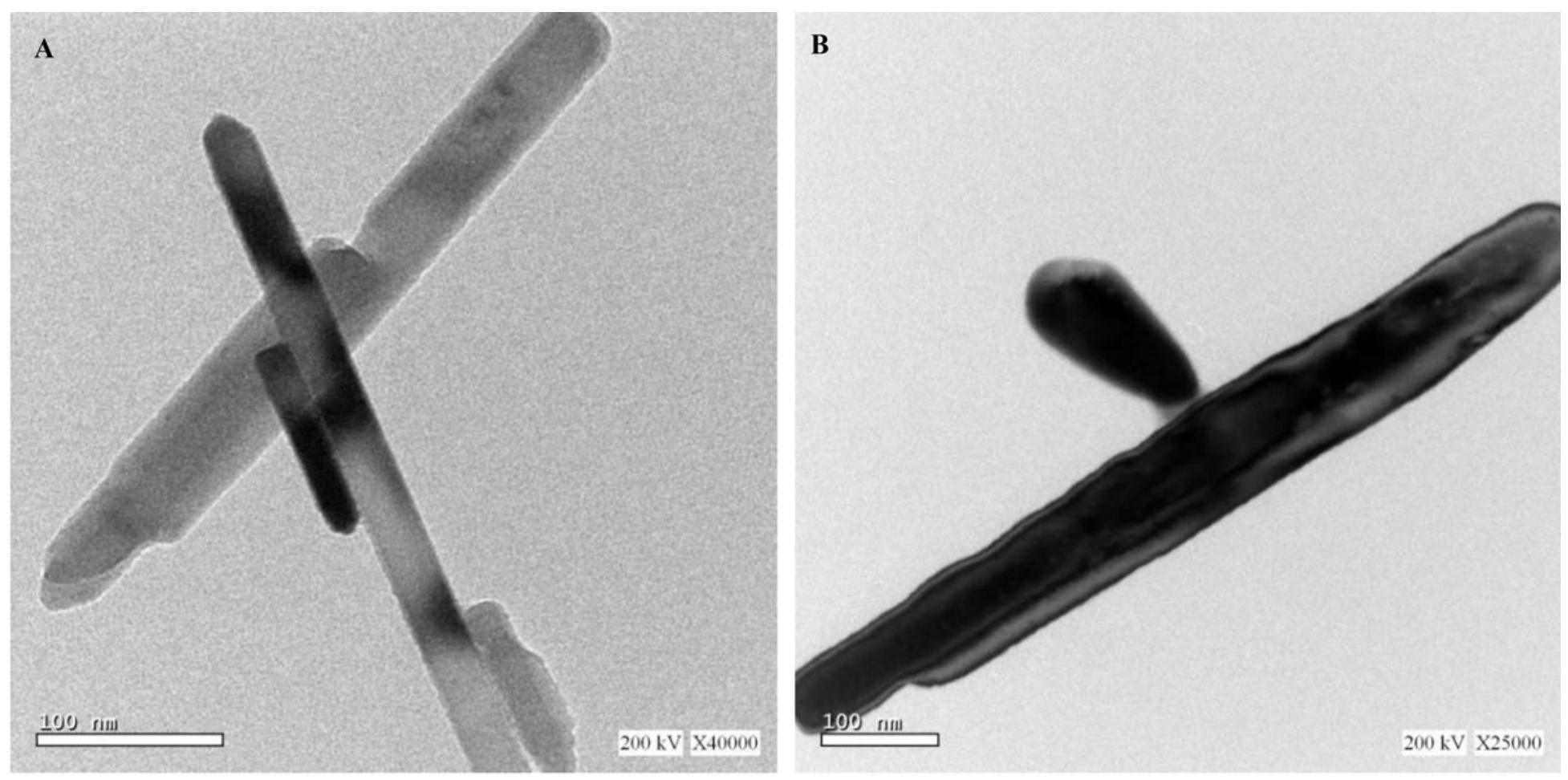

\section{Figure 3}

HRTEM images of ZnO-NPs prepared with (A) chemical and (B) green methods.
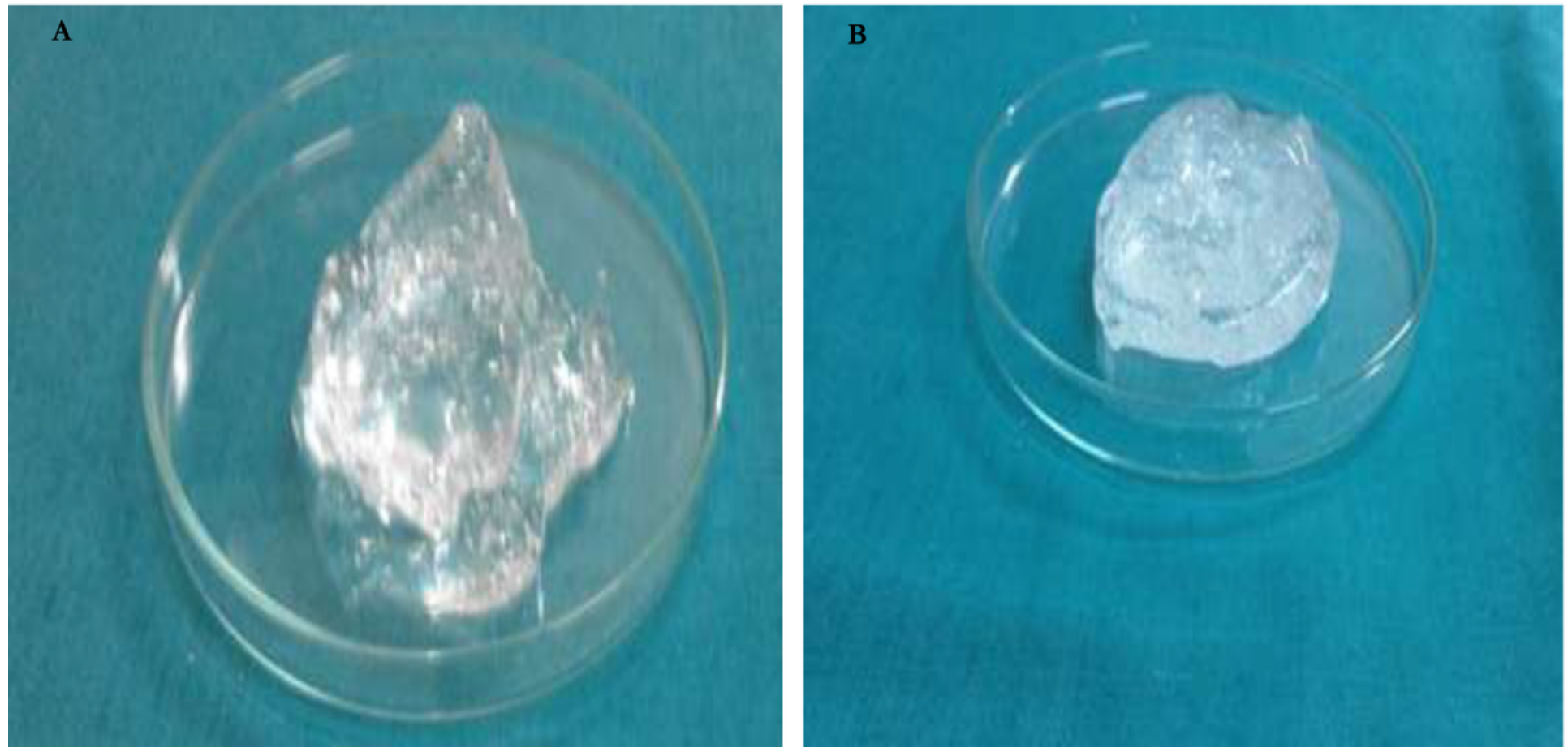

\section{Figure 4}

Photographs of the macroscopic appearance (A) Chemical ZnO Nano gel (transparent in color), and (B) Green ZnO Nano gel (transparent in color). 


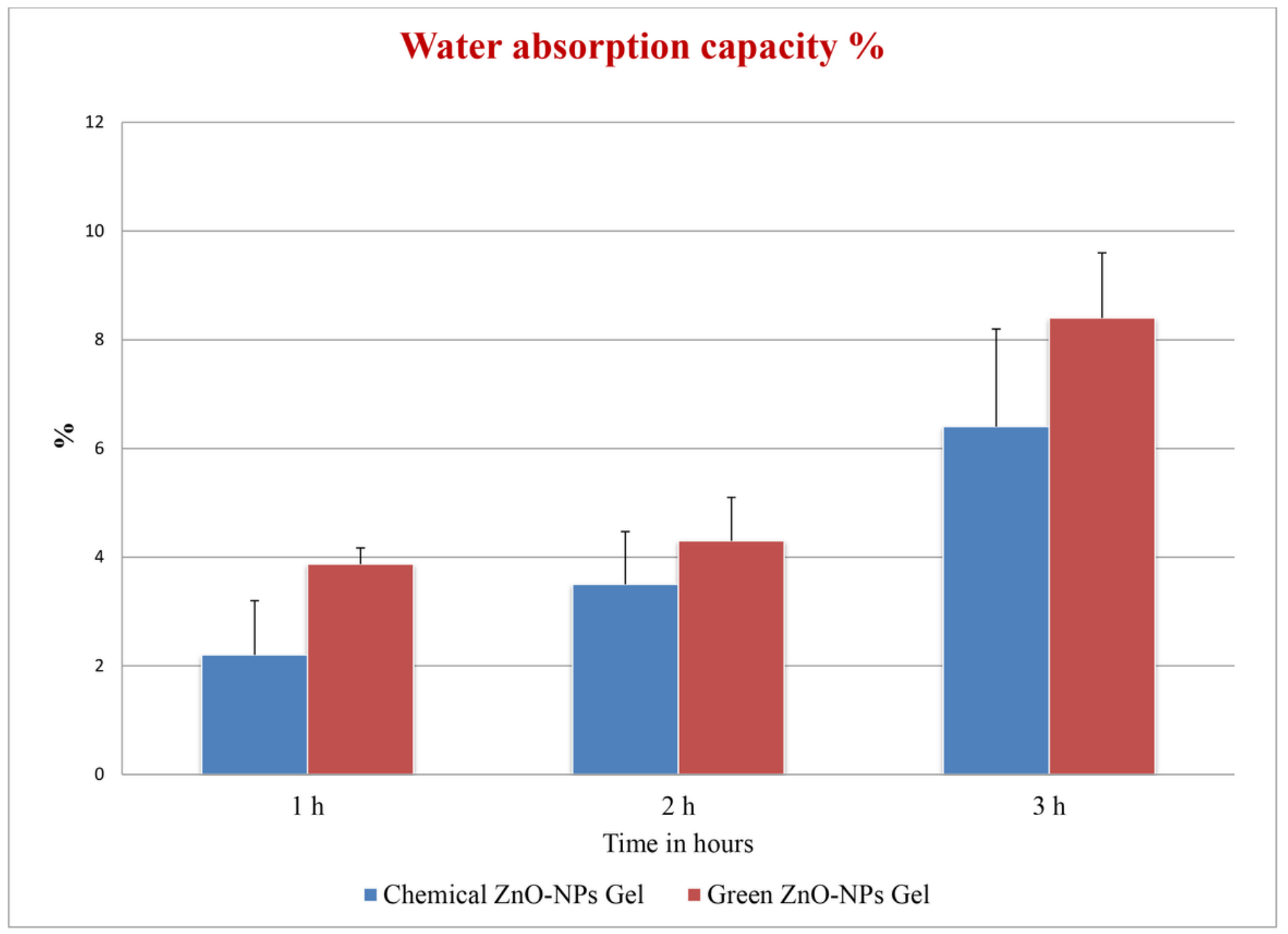

Figure 5

The mean + SD of water absorption capacity $\%$ of nanoparticles. 
Day 3

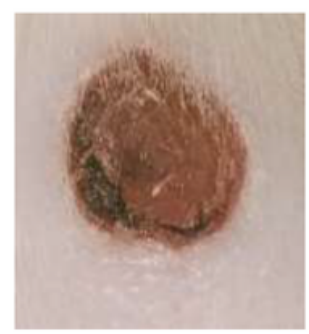

Control

Chemical $\mathrm{ZnO}-\mathrm{NPS}$
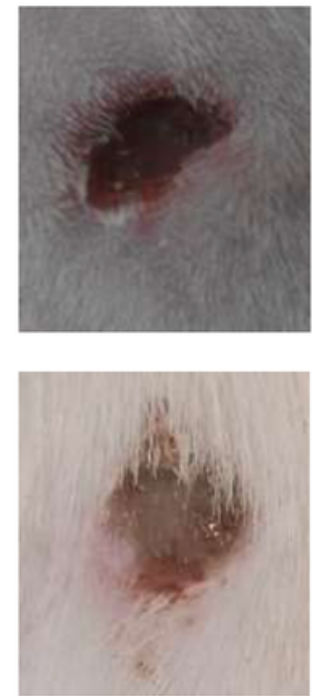

Day 7
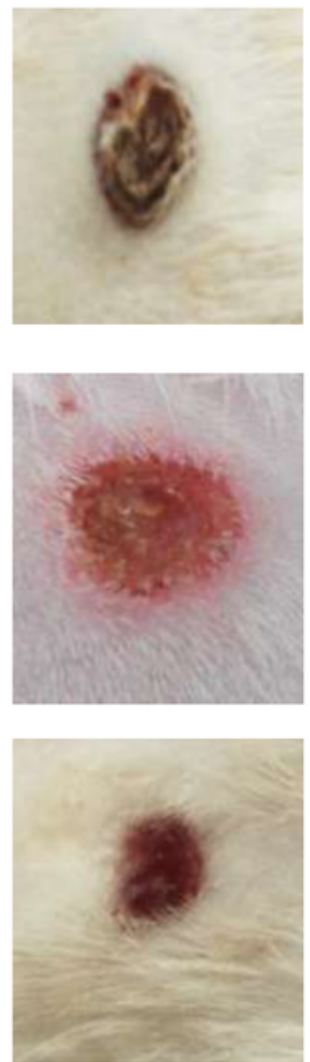

Day 14
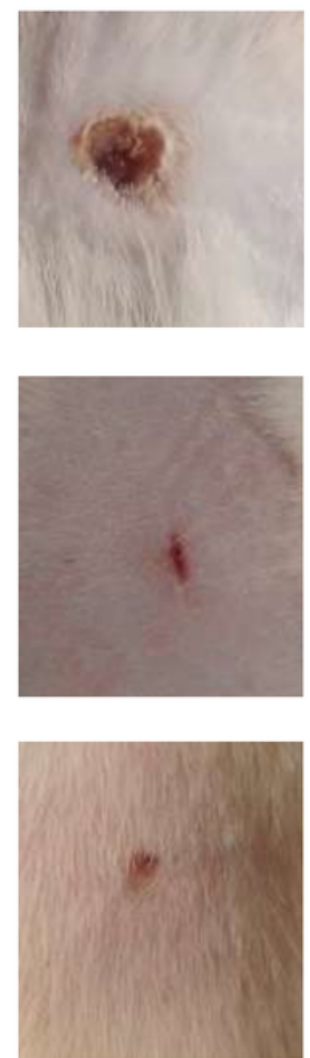

Day 21
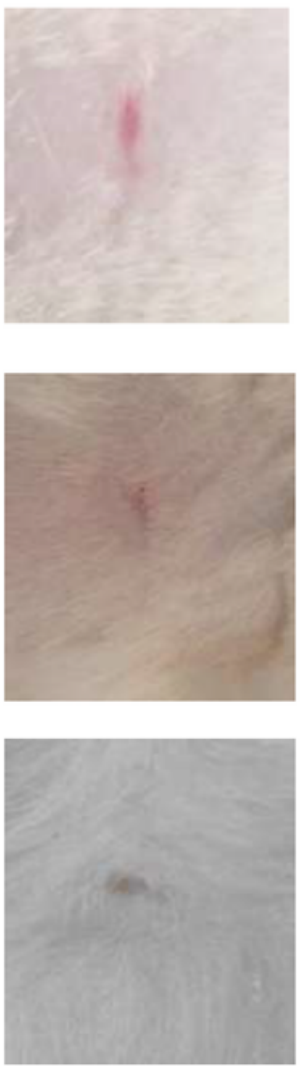

\section{Figure 6}

Photographs show the stages of wound healing of the control and treated groups (green and chemical ZnO-NPs) at the 3rd, 7th, 14th, and 21st days PT. 


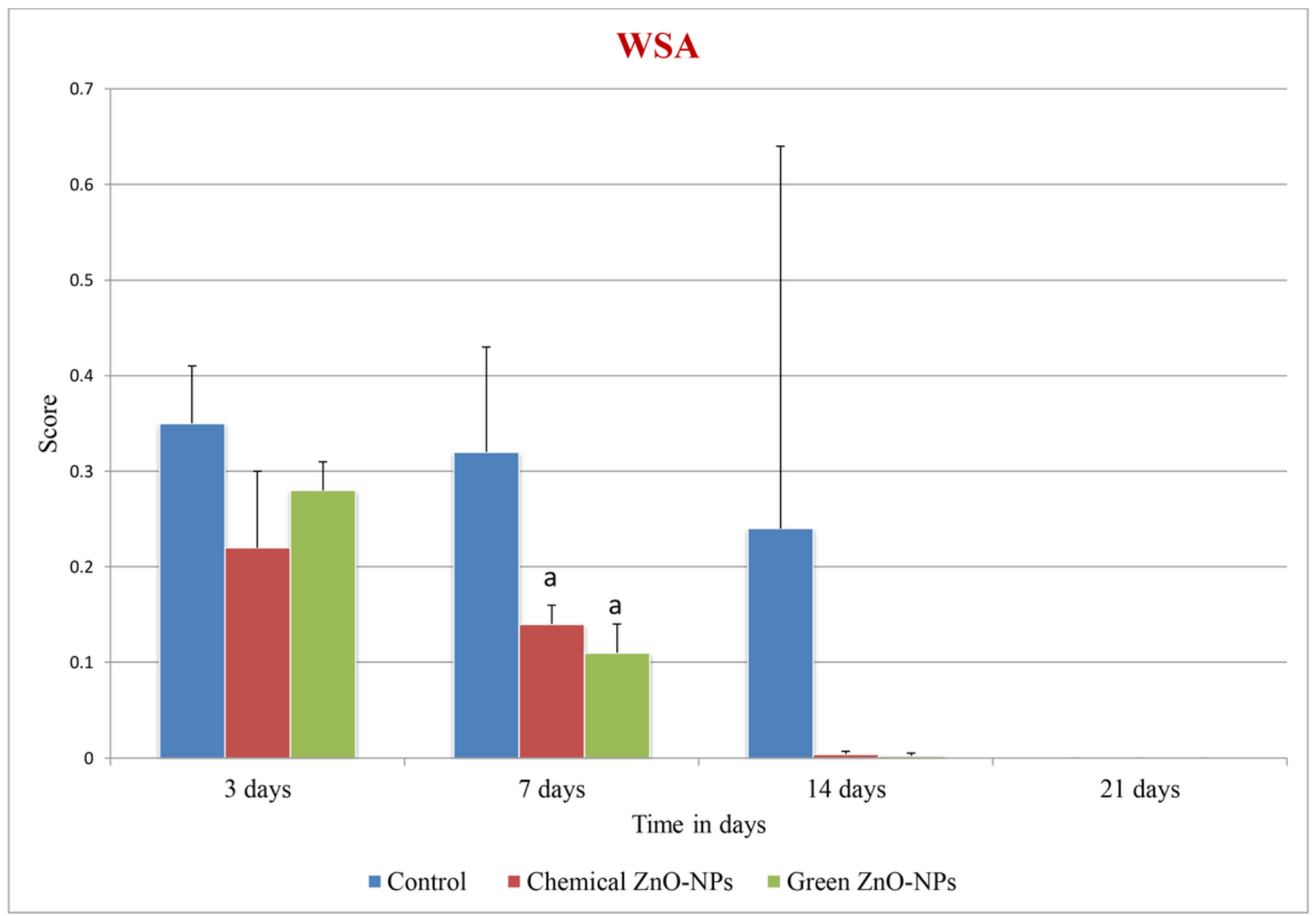

\section{Figure 7}

The mean + SD of wound surface area (WSA) for control and treated groups. (a): Significant changes when compared with control group when $p \leq 0.05$. 


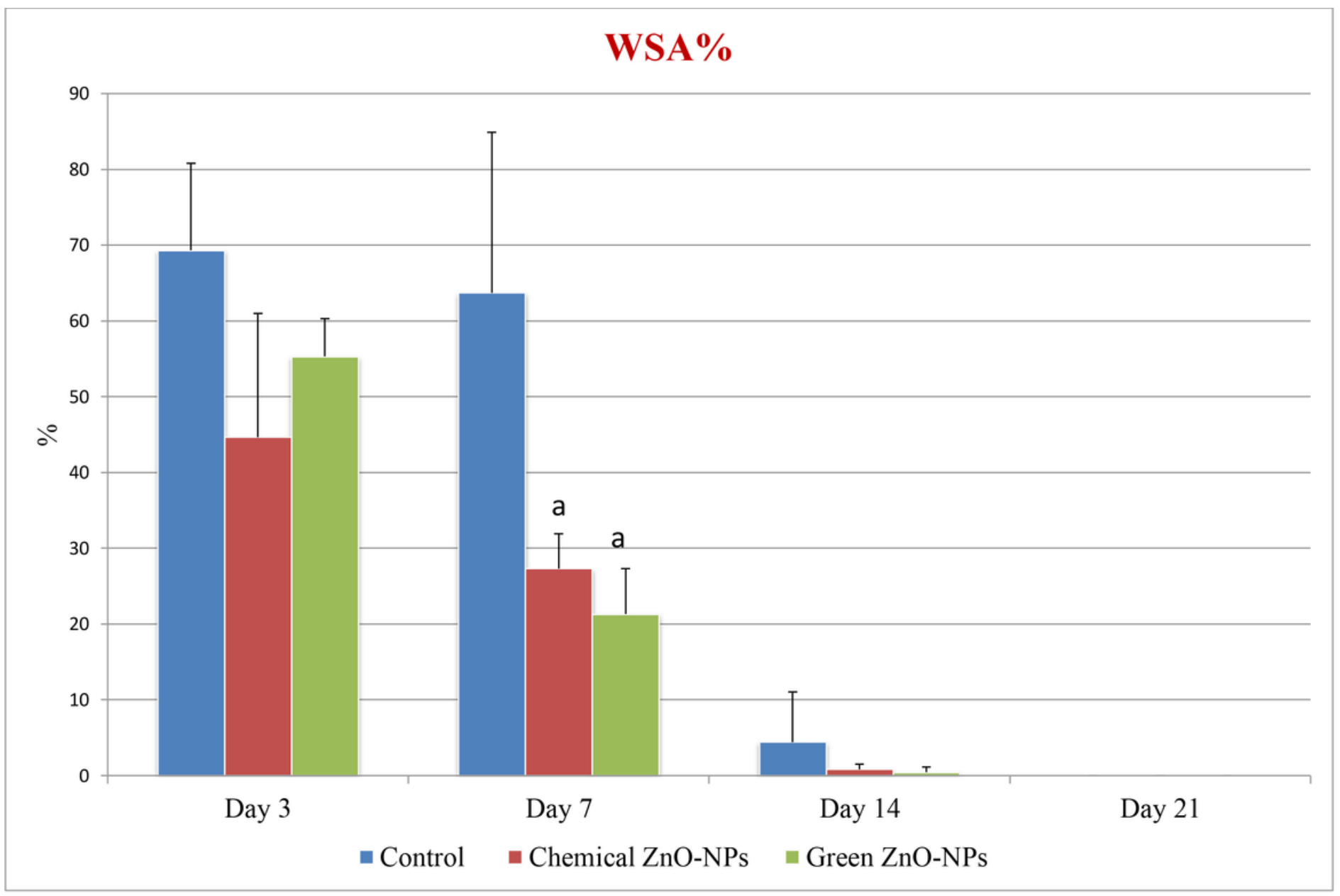

\section{Figure 8}

The mean + SD of wound surface area percent for control and treated groups. (a): Significant changes when compared with control group when $p \leq 0.05$. 


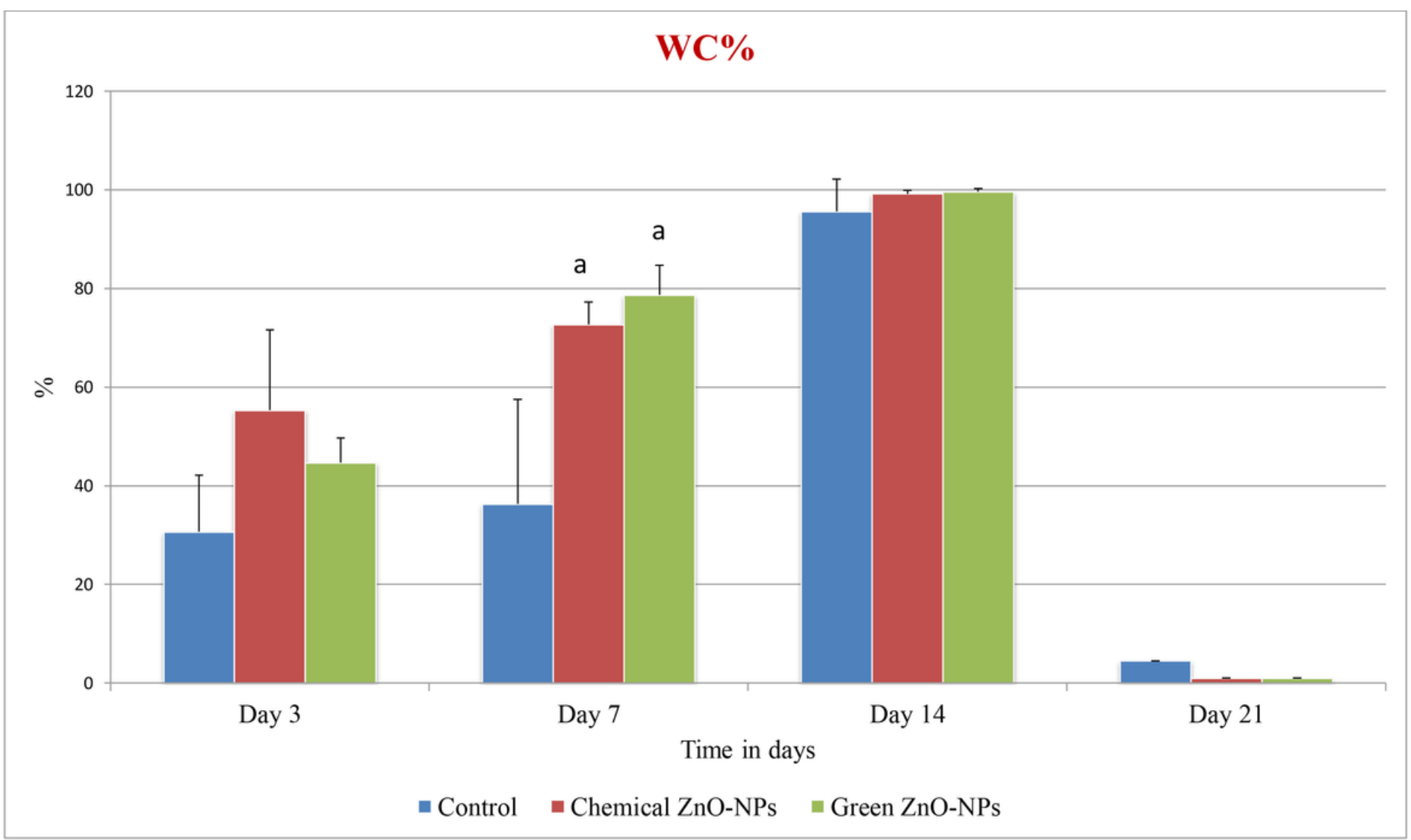

Figure 9

The mean + SD of wound contraction percent for control and treated groups. (a): Significant changes when compared with control group when $p \leq 0.05$. 


\section{Healing time}

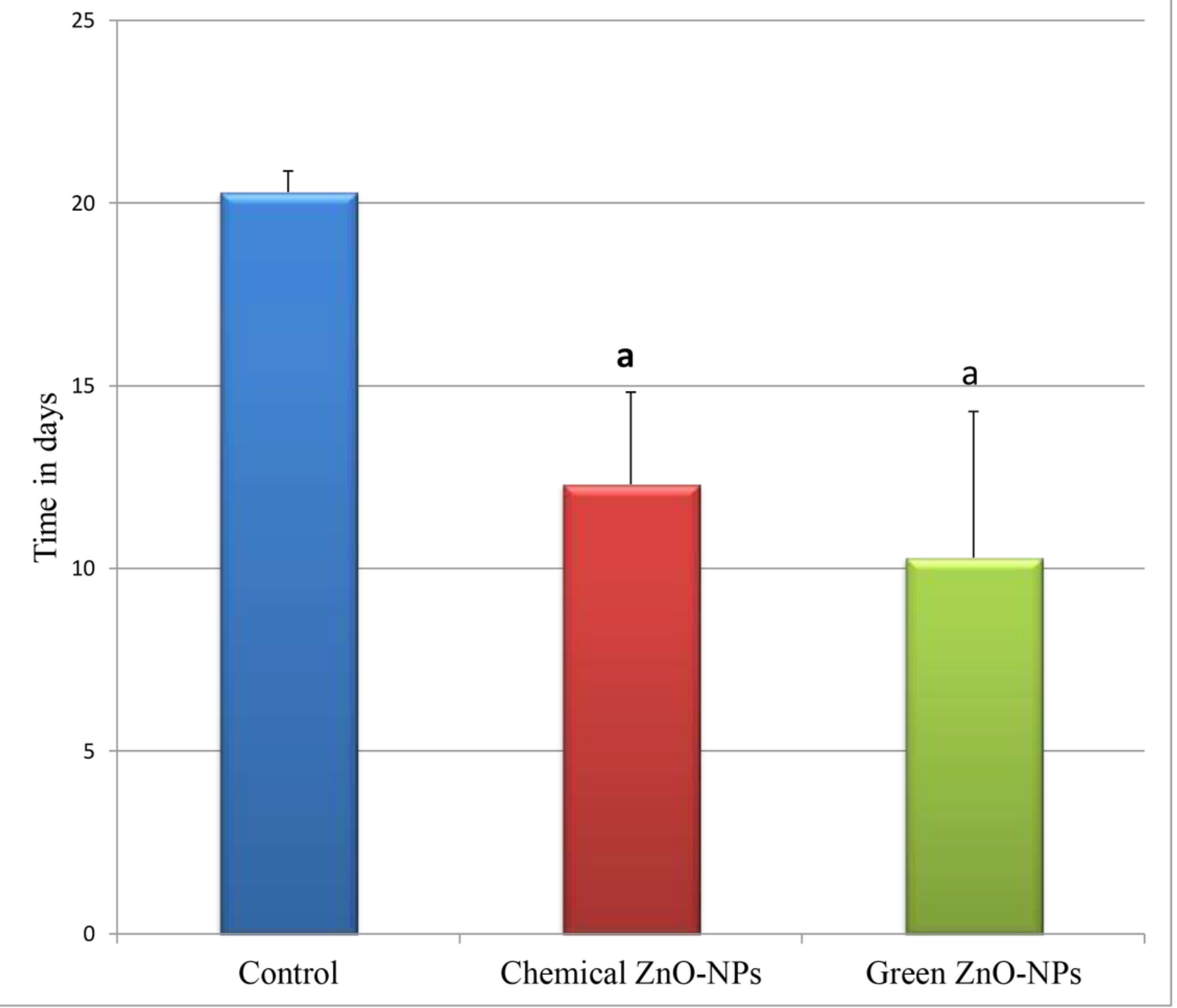

Figure 10

the mean + SD of healing time of full thickness skin wounds in control and treated groups. (a):

Significant changes when compared with control group when $p \leq 0.05$. 


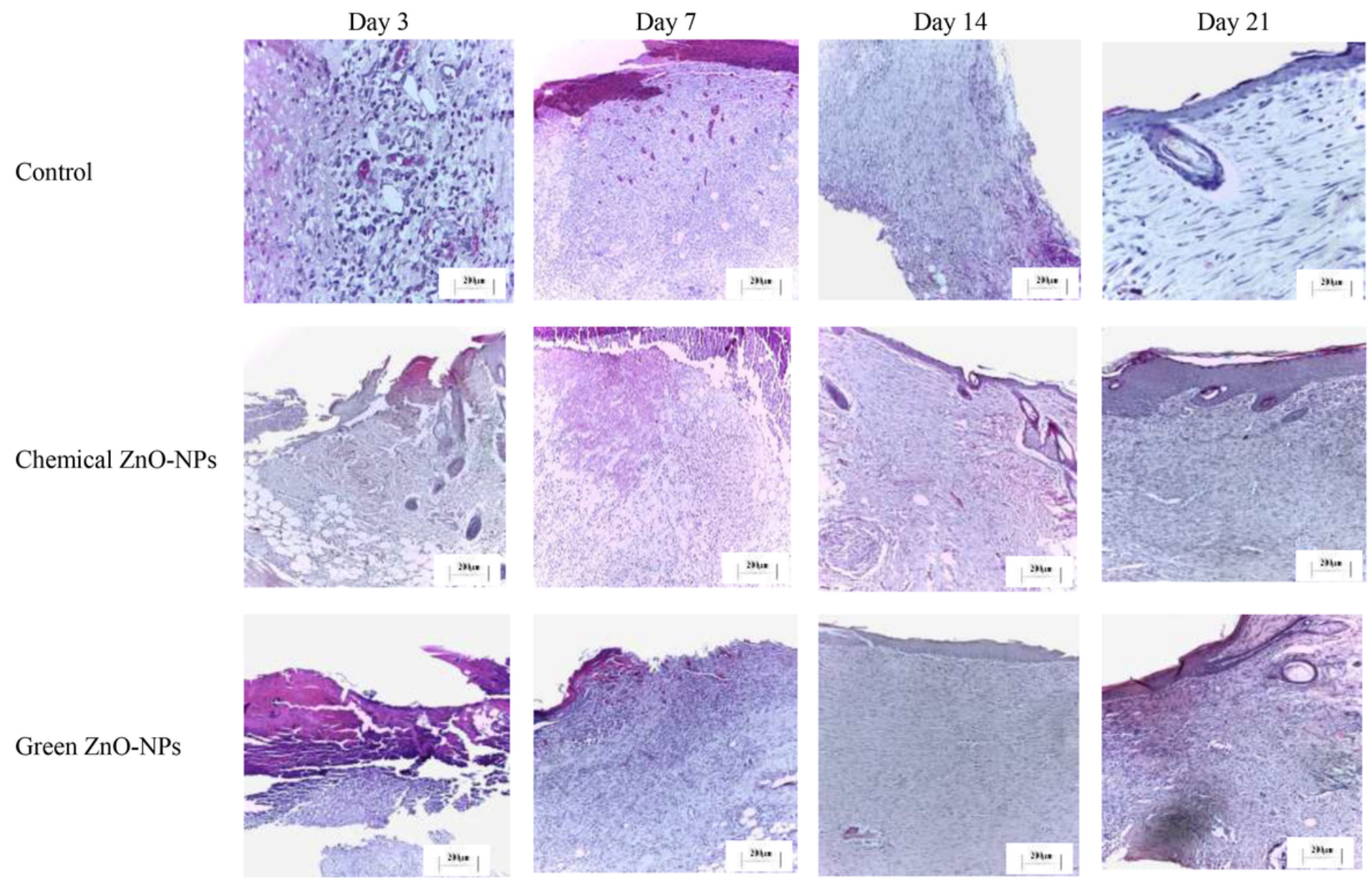

\section{Figure 11}

Histopathological photos of the control and treated groups at 3rd, 7th, 14th and 21st days post treatment $(H \& E .$, bar $=200 \mu m)$ 

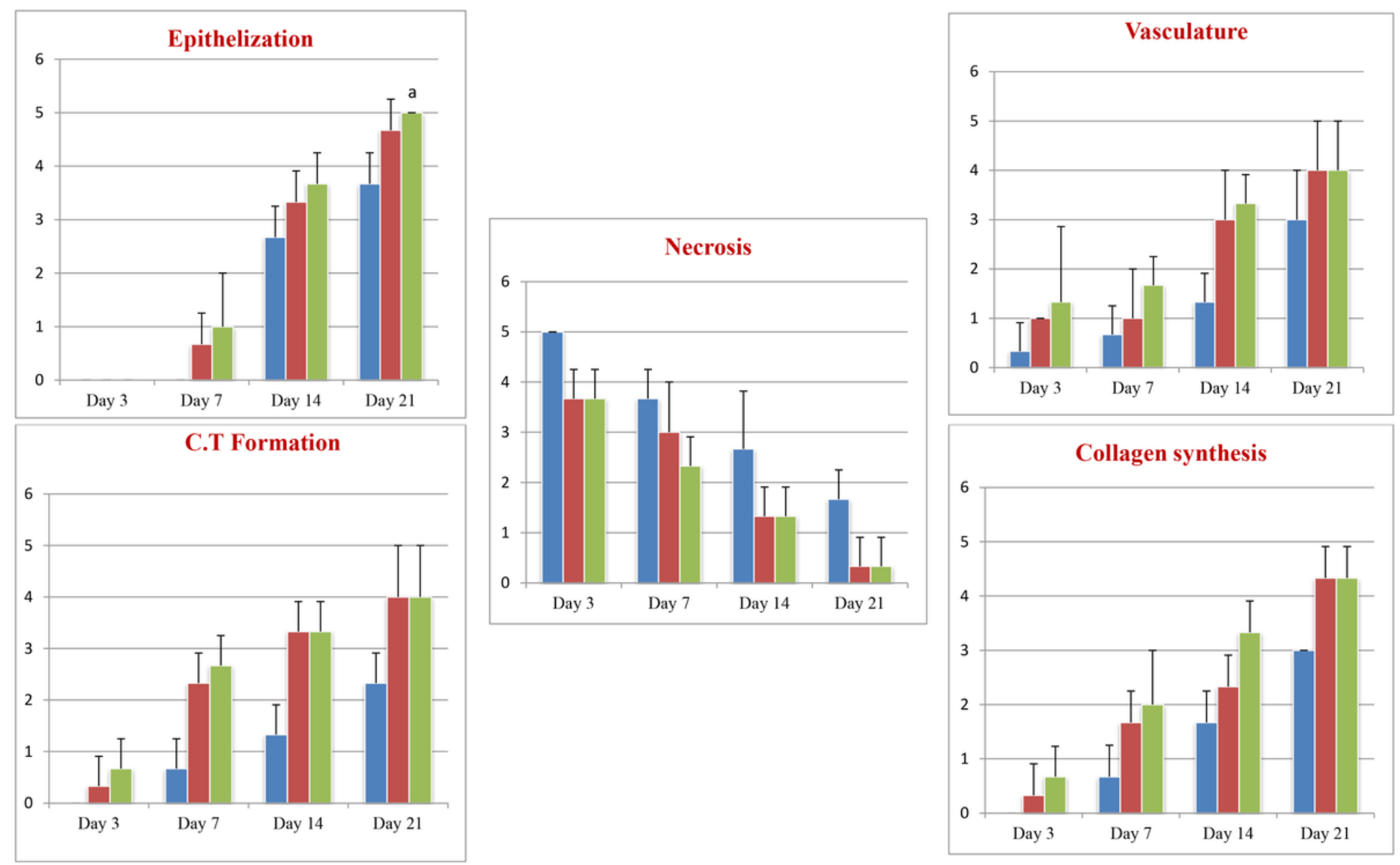

\section{Figure 12}

Histopathological scoring, the means + SD of epithelization, vasculature, necrosis, connective tissue formation and collagen synthesis in full thickness skin wounds in control and treated groups. Control (blue), chemical ZnO-NPs (red) and green ZnO-NPs (green)

\section{Supplementary Files}

This is a list of supplementary files associated with this preprint. Click to download.

- Graphicalabstract.pdf 